\title{
The effects of the order of picture presentation on the subjective emotional evaluation of pictures
}

\author{
Vladimir Kosonogov ${ }^{1}$ \\ ${ }^{1}$ HSE University
}

\begin{abstract}
In the last twenty years, a great number of studies on subjective emotional evaluation of affective pictures have been published. However, it is well-known that the order of presentation may entail sequential effects, which is the perception of a previous stimulus that may influence the next stimulus's perception. Our study examines whether the order of picture presentation influences the subjective evaluation of their affective valence and arousal. The results showed some influence of the order of presentation on affective valence: unpleasant pictures at the end were less unpleasant than unpleasant pictures at the beginning, and the neutral picture, when presented after unpleasant pictures, was more pleasant than when presented after pleasant pictures. No effect of presentation order on arousal was found. These findings suggest that several picture presentation orders should be used in future experiments on emotions to avoid possible effects of the order on affective valence.
\end{abstract}

\section{Keywords: Affective pictures; order of presentation; affective valence; arousal.}

Os efeitos da ordem de apresentação das imagens na avaliação emocional subjetiva das imagens: Nos últimos vinte anos, um grande número de estudos sobre avaliação emocional subjetiva de imagens afetivas foi publicado. No entanto, é sabido que a ordem de apresentação pode acarretar efeitos sequenciais, ou seja, a perceção de um estímulo anterior pode influenciar a perceção do próximo estímulo. Este estudo examinou se a ordem de apresentação da imagem influencia a avaliação subjetiva da sua valência afetiva e excitação. Os resultados mostraram alguma influência da ordem de apresentação na valência afetiva: imagens desagradáveis no final foram avaliadas como menos desagradáveis do que imagens desagradáveis apresentadas no início, e a imagem neutras, quando apresentada após imagens desagradáveis, era avaliada como mais agradável do que quando apresentada após imagens agradáveis. Nenhum efeito da ordem de apresentação na excitação foi encontrado. Várias ordens de apresentação de imagens devem ser usadas em estudos futuros sobre emoções para evitar possíveis efeitos da ordem na valência afetiva.

\section{Palavras-chave: Imagens afetivas; ordem de apresentação; valência afetiva; excitação.}

In the last twenty years, a significant number of studies on subjective emotional evaluation of affective pictures have been published. In some studies, researchers used several orders of randomly mixed pictures to avoid possible effects of the order of picture presentation on the evaluation (e.g., Schlenker et al., 1995), but in other studies, only one order of pictures was used that might have influenced the evaluation (e.g., Kovalenko et al., 2010). However, it is well-known that the order of presentation may entail sequential effects, which is the perception of a previous stimulus that may influence the next stimulus's perception. Thus, Kondo et al. (2012) showed that the attractiveness rating of a given face assimilated toward the preceding trial rating. Damisch et al. (2006) found that an Olympic gymnast's likelihood to receive a high score for their exercise is higher if the preceding gymnast presented a good rather than a poor performance. In a study by Stewart et al. (2005), recognition of tones was biased toward the immediately preceding stimuli but away from more distant stimuli (assimilation and contrast effects).

These effects could also influence the evaluation of affective stimuli and raise doubts about the results obtained without taking them into account. However, a similar experiment has not been conducted on the emotional evaluation of pictures. The presented study examines whether the order of presentation of affective pictures influences the participants' subjective emotional evaluation. Two typical, self-reported properties of affective pictures were used - affective valence, that is pleasantness/unpleasantness of a picture for participants (that entails approach or avoidance behavior), and arousal or subjective arousal,

\footnotetext{
${ }^{1}$ Correspondence address: Vladimir Kosonogov, Krivokolenny 3, Moscow, Russia, 101000. E-mail: vkosonogov@hse.ru

This study was supported by the HSE Basic Research Program and the Russian Academic Excellence Project '5-100' and used the HSE Synchronous Eye-tracking, Brain Signal Recording and Non-Invasive Brain Stimulation System.
} 
that is the power or strength, of the experienced emotion, in response to a picture (for reviews see Lang et al., 1997, Kensinger, 2004). The factor analysis method showed that emotions' physiological correlates could be reduced to these two dimensions (Sánchez-Navarro et al., 2008).

Two possible factors of the order of presentation were chosen - the position of a picture at the beginning or end of the experimental session (which might entail fatigue, habituation, or novelty effects), and the influence that the perception of an affective picture may exert on the next picture. Novelty or orienting effects might make the ratings at the beginning of the session more emotional (extreme affective valence points and a greater arousal). In contrast, fatigue, extinction, or habituation might make pictures more neutral (or less unpleasant and less pleasant) and diminish pictures' arousal ratings at the end of the session. A possible effect of a previous picture on the next one might be put down to the priming effect (Bargh and Chartrand, 2000), which consists of the exposure of a stimulus on the next one, regardless of the participants' awareness. Another possible explanation would be a conscious intention to balance ratings, taking into account previous pictures' ratings. For example, "I rated the previous picture with 7, and this one is more pleasant; hence, it should be rated higher, with 8 or 9".

Therefore, the first objective of this experiment was to study the possible effects of the position of a picture, at the beginning or end of the experimental session, on its affective valence and arousal. The second objective was to check whether the perception of an affective picture may influence the affective valence and arousal of the next picture.

\section{METHOD}

\section{Participants}

A sample of 89 university students ( 45 females, 44 males; $M_{a g e}=24.8, S D_{a g e}=4.7$ ) participated in the experiment. All subjects gave informed consent and received course credits for participation in the experiment. All procedures were conducted in accordance with the Declaration of Helsinki.

\section{Stimuli}

Thirty-three photographic pictures (10 unpleasant, 13 neutral, and ten pleasant) from the Internet were used in the study. Some of them were presented several times; the total number of trials was 70 (Figure 1). Fourteen pictures were experimental (i.e., their data were statistically analyzed), and 19 were control (i.e., they were presented before experimental pictures, and their data were not analyzed). Seven experimental pictures (three unpleasant pictures of different arousal, depicting garbage, rebels, and mutilation; one neutral picture, depicting working people; and three pleasant pictures of different arousal, depicting nature, food, and erotica) were presented twice - at the beginning (within trials 1-14) and at the end (within trials 57-70) of the session, each being presented after one of the neutral control pictures (household objects). The other seven experimental pictures (three unpleasant, one neutral, and three pleasant ones depicting similar events or objects as the seven pictures mentioned above) were presented three times (within trials 15-56) - after one of control unpleasant (mutilation), one of control neutral (household objects), and one of control pleasant pictures (erotica). This unequal number of pictures (three unpleasant of different arousal, one neutral, and three pleasant of different arousal) was used because, usually, the affective valence of unpleasant and pleasant pictures varies more than the affective valence of neutral ones (Amrhein et al., 2004, Kosonogov et al., 2019). All the pictures were of the same size (800 × 600 pixels) and color depth (24 bits) and were presented in full-screen mode. Not more than three successive pictures of the same affective valence were allowed. 


\section{Question 1:}

Do affective valence and arousal differ at the beginning vs. end of the experimental session?
1 unpleasant, low arousal (garbage)

1 unpleasant, middle arousal (rebels)

1 unpleasant, high arousal (mutilation)

1 neutral, low arousal (workers)

1 pleasant, low arousal (landscape)

1 pleasant, middle arousal (food)

1 pleasant, high arousal (erotica)

presented twice after a neutral control picture (household objects)

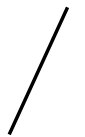

beginning trials (1-14)

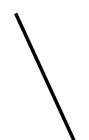

end trials (57-70)

\section{Question 2:}

Do affective valence and arousal differ

if the picture is presented after an unpleasant vs. neutral vs. pleasant picture?

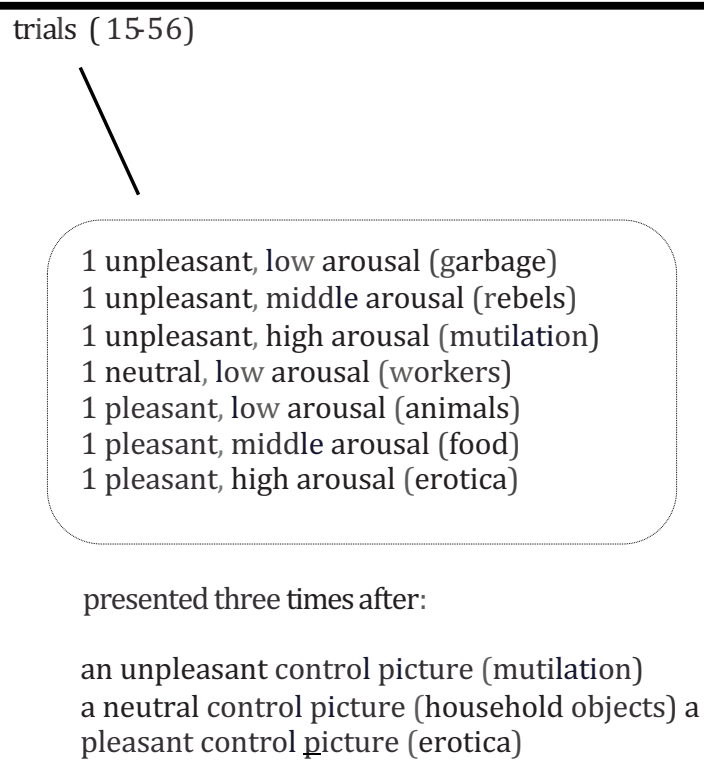

Figure 1. The design of the study.

\section{Procedure}

Each participant sat alone in a classroom, in front of a 44-cm monitor (it was one monitor with the same settings for all participants), watched at a time one picture as long as they wanted (a free-viewing paradigm), and clicked with the mouse on buttons which indicated points of affective valence and arousal from 1 to 9 (1 meant "very unpleasant" and "no arousal," and 9 meant "very pleasant" and "very arousing," respectively). Participants could not go back to change their evaluation of previous pictures. Neither could they skip a picture. The experiment was conducted in a graphical experiment builder OpenSesame 3 (Mathôt et al., 2012). The free-viewing paradigm was chosen because it was shown previously that more arousing pictures (i.e., unpleasant and pleasant versus neutral) required more time to be processed and evaluated (Hamm et al., 1997, Ritz et al., 2005). It was impossible to use more affective pictures due to the time restriction of the session. Not more than three successive pictures of the same affective valence were allowed.

\section{Data analysis}

Differences between affective valence and arousal ratings at the beginning and end of the session were analyzed with paired $t$-tests. A potential effect of the perception of an affective picture on the next picture's valence and arousal was studied with an analysis of variance with repeated measures with the Bonferroni pairwise comparisons. 


\section{RESULTS}

\section{Control pictures}

Control pictures received the expected ratings. Unpleasant pictures were rated with $1.94(S D=1.78)$ points of affective valence and $6.97(S D=2.55)$ points of arousal. Neutral pictures received $5.02(S D=0.97)$ points of affective valence and $2.83(S D=2.04)$ points of arousal. Pleasant pictures were rated with $7.48(S D=$ $2.05)$ points of affective valence and $7.11(S D=2.32)$ points of arousal. These data are consistent with the pictures widely used in literature and allow us to conduct further analysis of experimental pictures.

\section{Experimental pictures}

The descriptive statistics of affective valence, at the beginning and end of the session, are presented in Table 1. The unpleasant pictures at the end of the session were less unpleasant than the unpleasant pictures at the beginning, $t(88)=2.56, p=.012$, Cohen's $d=0.27,95 \%$ CI $[0.06,0.48], 1-\beta=.81$. The affective valence of neutral pictures did not differ at the beginning and end of the session, $t(88)=0.72, p=.480$. The affective valence of pleasant pictures did not differ at the beginning and end of the session either, $t(88)=0.81, p=$ .420 .

Table 1. Affective Valence Ratings of Pictures at the Beginning and End of the Session

\begin{tabular}{ccccc}
\hline & \multicolumn{2}{c}{ At the beginning } & \multicolumn{2}{c}{ At the end } \\
\cline { 2 - 5 } & $M$ & $S D$ & $M$ & $S D$ \\
\hline Unpleasant & $2.43^{\mathrm{a}}$ & 1.38 & $2.73^{\mathrm{a}}$ & 1.45 \\
Neutral & 5.01 & 1.02 & 5.09 & 1.05 \\
Pleasant & 7.36 & 1.36 & 7.24 & 1.24 \\
\hline
\end{tabular}

The superscript means that the indicated values were significantly different.

Table 2 displays the descriptive statistics of the affective valence of the pictures presented after different affective pictures ${ }^{2}$. The effect of the perception of a previous affective picture on the valence of the next neutral picture was significant, $F(2,176)=3.48, p=.040, \eta_{p}^{2}=.038,1-\beta=.95$. Post hoc pairwise comparisons showed that neutral pictures, presented after unpleasant pictures, were more pleasant than neutral pictures presented after pleasant pictures, $p=.025$, Cohen's $d=0.24,95 \%$ CI $[0.03,0.45]$. The effect of the perception of a previous affective picture, on the valence of the next unpleasant picture, was not significant, $F(2,176)=2.29, p=.111, \eta_{p}^{2}=.025$. The effect of the perception of a previous affective picture on the next pleasant picture's valence was not significant either, $F(2,176)=1.78, p=.175, \eta_{p}^{2}=.020$.

Table 2. Affective Valence Ratings of the Pictures, Presented After the Pictures of Different Affective Valence

\begin{tabular}{ccccccc}
\hline & \multicolumn{2}{c}{ After unpleasant pictures } & \multicolumn{2}{c}{ After neutral pictures } & \multicolumn{2}{c}{ After pleasant pictures } \\
\cline { 2 - 6 } & $M$ & $S D$ & $M$ & $S D$ & $M$ & $S D$ \\
\hline Unpleasant & 2.71 & 1.28 & 2.91 & 1.41 & 2.71 & 1.38 \\
Neutral & $5.25^{\mathrm{a}}$ & 1.23 & 5.08 & 1.09 & $5.00^{\mathrm{a}}$ & 0.99 \\
Pleasant & 7.43 & 1.29 & 7.34 & 1.30 & 7.49 & 1.26 \\
\hline
\end{tabular}

The superscript means that the indicated values were significantly different.

The descriptive statistics of arousal at the beginning and end of the session are presented in Table 3. We did not find any effect of a picture's position at the beginning or end of the experimental session on its arousal. The arousal of unpleasant pictures did not differ at the beginning and end of the session, $t(88)$ $=0.26, p=.787$. The arousal of neutral pictures did not differ at the beginning and end of the session, $t(88)$ $=0.06, p=.950$. The arousal of pleasant pictures did not differ at the beginning and end of the session either, $t(88)=1.62, p=.110$.

\footnotetext{
${ }^{2} \mathrm{~A}$ paired $t$-test of the pictures presented at the beginning and end showed that the arousal of pleasant pictures was greater than the arousal of unpleasant pictures ( $M=6.79$ vs. $M=4.25), t(88)=7.58, p=.001$, Cohen's $d=1.41$. In the same vein, a paired $t$-test of the pictures, presented in the middle trials (that tested the second hypothesis), showed that the arousal of pleasant pictures was greater than the arousal of unpleasant pictures $(M=7.59$ vs. $M=5.18), t(88)=7.76, p=.001$, Cohen's $d=1.42$. This will be discussed in a limitation paragraph in Discussion.
} 
Table 3. Arousal Ratings of the Pictures at the Beginning and End of the Session

\begin{tabular}{ccccc}
\hline & \multicolumn{2}{c}{ At the beginning } & \multicolumn{2}{c}{ At the end } \\
\cline { 2 - 5 } & $M$ & $S D$ & $M$ & $S D$ \\
\hline Unpleasant & 4.27 & 2.63 & 4.23 & 2.59 \\
Neutral & 3.80 & 1.98 & 3.79 & 1.92 \\
Pleasant & 6.70 & 1.62 & 6.89 & 1.58 \\
\hline
\end{tabular}

Table 4 displays the descriptive statistics of the arousal of the pictures presented after different affective pictures. The effect of the perception of a previous affective picture, on the arousal of the next unpleasant picture, was not significant, $F(2,176)=0.24, p=.788, \eta_{p}^{2}=.003$. The effect of the perception of a previous affective picture on the next neutral picture's arousal was not significant either, $F(2,176)=1.06$, $p=.340, \eta_{p}{ }^{2}=.012$. Finally, the effect of the perception of a previous affective picture on the next pleasant picture's arousal was not significant, $F(2,176)=2.47, p=.088, \eta_{p}^{2}=.027$.

Table 4. Arousal Ratings of the Pictures, Presented After the Pictures of Different Affective Valence

\begin{tabular}{ccccccc}
\hline & \multicolumn{2}{c}{ After unpleasant pictures } & \multicolumn{2}{c}{ After neutral pictures } & \multicolumn{2}{c}{ After pleasant pictures } \\
\cline { 2 - 7 } & $M$ & $S D$ & $M$ & $S D$ & $M$ & $S D$ \\
\hline Unpleasant & 5.16 & 2.86 & 5.21 & 2.77 & 5.15 & 2.92 \\
Neutral & 3.91 & 2.04 & 3.74 & 1.99 & 3.70 & 1.84 \\
Pleasant & 7.64 & 1.28 & 7.49 & 1.37 & 7.62 & 1.30 \\
\hline
\end{tabular}

\section{DISCUSSION}

The aim of the study was to examine whether the order of affective pictures influences the subjective evaluation of them in terms of affective valence and arousal. Two types of variables were studied - the position of a picture at the beginning or end of the 70-trial presentation and the picture's position after an unpleasant, neutral, or pleasant picture. Both control and experimental pictures received the expected ratings (correspondent with, for example, the data of Bradley et al., 2001). The results show that only affective valence was slightly modulated by the sequence effects.

Unpleasant pictures at the end of the session were less unpleasant than unpleasant pictures at the beginning. In other words, the affective valence of unpleasant pictures increased, and they became less unpleasant at the end. There could be two explanations for these data. First, extinction or habituation could diminish the stressful impact of unpleasant pictures. However, it should be noted that all pictures' subjective arousal did not change at the end of the session, compared with the beginning, which would also have happened if extinction, or habituation, had influenced the evaluation. Hence, the second explanation is more plausible - the unpleasant pictures, presented at the beginning, greatly stressed the participants (orienting response, albeit not measured physiologically in our study; Sokolov, 1960), But, at the end, participants evaluated the unpleasant pictures (the same ones at the beginning), firstly, taking into account all unpleasant pictures in the experiment, and compared their affective valence, and, secondly, when the orienting effect had already disappeared. The same effect was not found for neutral and pleasant pictures, probably, because the orienting reflex is more salient in response to unpleasant stimuli, as shown in startle eyeblink studies (Vrana et al., 1988). This can be referred to as negativity bias - a construct that describes our predisposition to attend to and be more affected by a negative experience (Haizlip et al., 2012) that may play an important role in survival. However, interestingly, repeated presentation attenuated the negativity, whereas pleasant pictures' valence was not changed.

When presented after unpleasant pictures, the neutral picture was rated as that when presented after pleasant pictures. This means that people overestimate a neutral picture's pleasantness if they have just watched an unpleasant picture previously. These data may indirectly reflect negativity bias as well the enhanced attention to a previously observed unpleasant picture makes us evaluate the next neutral picture by comparing them. This is why the contrast is noted better, and the neutral picture becomes more pleasant.

Interestingly, no effect of the order of picture presentation on subjective arousal was found. This means that this feature of affective pictures is stable and is not subject to the influence of pictures' order. First, it can be suggested that there was no extinction or habituation. On the other hand, usually, subjective arousal has a greater standard deviation than affective valence, which may mean that subjective arousal is a vaguer concept, which is hard for participants to use. Thus, in our study, standard deviations of arousal were up to two times greater than standard deviations of affective valence, which impede the search for significant differences between mean values of arousal. This is why they may attribute arousal ratings to pictures less consciously without comparing different pictures. 
This study has some limitations that could be avoided in future research. Thus, a small number of pictures were used (overall, 14 experimental pictures), but the study's design required a great number of control pictures. Moreover, the pictures had not been validated or published previously. However, the pictures received the expected ratings, corresponding with the well-known data. For example, the mutilation pictures are more unpleasant than household objects. It turned out that unpleasant and pleasant pictures were not balanced by arousal. But our comparisons were conducted within an affective category (i.e., pleasant pictures were compared only with pleasant ones), and, in general, not always researchers balance the arousal of pleasant and unpleasant pictures, depending on the aim of their study (e.g., Wangelin et al., 2011). Future research should employ more pictures of a greater affective spectrum and different themes because some themes have their unique influence on participants. For example, mutilation pictures can make human posture "freeze" (Azevedo et al., 2015).

However, the study showed that the order of picture presentation could influence the subjective evaluation of affective pictures. The affective valence of affective pictures can be influenced by the position of pictures in the experimental session (unpleasant pictures at the end are less unpleasant than at the beginning) and by the affective valence of pictures presented previously (neutral pictures are more pleasant if presented after an unpleasant one). Therefore, in designs with only one order of picture presentation, this may hinder the measurement of other variables under study. To conclude, it can be recommended to use several orders of presentation of pictures to avoid possible influences of order on affective valence.

\section{REFERENCES}

Amrhein, C., Mühlberger, A., Pauli, P., \& Wiedemann, G. (2004). Modulation of event-related brain potentials during affective picture processing: a complement to startle reflex and skin conductance response? $\begin{array}{lllll}\text { International of Journal } & \text { Psychophysiology, } & \text { 54, } & \text { 231-240. }\end{array}$ https://doi.org/10.1016/j.ijpsycho.2004.05.009

Azevedo, T. M., Volchan, E., Imbiriba, L. A., Rodrigues, E. C., Oliveira, J. M., Oliveira, L. F., Lutterbach, L. G.,\& Vargas, C. D. (2005). A freezing-like posture to pictures of mutilation. Psychophysiology, 42, 255-260. https://doi.org/10.1111/j.1469-8986.2005.00287.x

Bargh, J. A., Chartrand, T. L. (2000). Studying the mind in the middle: A practical guide to priming and automaticity research. In Reis H, Judd C (eds.), Handbook of Research Methods in Social Psychology (pp. 1-39). Cambridge University Press.

Bradley, M. M., Codispoti, M., Cuthbert, B. N., \& Lang, P. J. (2001) Emotion and motivation I: Defensive and appetitive reactions in picture processing. Emotion, 1, 276-298. https://doi.org/10.1037/15283542.1.3.276

Damisch, L., Mussweiler, T., \& Plessner, H. (2006). Olympic medals as fruits of comparison? Assimilation and contrast in sequential performance judgments. Journal of Experimental Psychology: Applied, 12, 166-178. https://doi.org/10.1037/1076-898X.12.3.166

Haizlip, J., May, N., Schorling, J., Williams, A., \& Plews-Ogan, M. (2012). Perspective: the negativity bias, medical education, and the culture of academic medicine: Why culture change is hard. Academic Medicine, 87, 1205-1209. https://doi.org/10.1097/ACM.0b013e3182628f03

Hamm, A. O., Cuthbert, N. B., Globish, J., \& Vaitl, D. (1997). Fear and the startle reflex: Blink modulation and autonomic response patterns in animal and mutilation fearful subjects. Psychophysiology, 34, 97107. https://doi.org/10.1111/j.1469-8986.1997.tb02420.x

Kensinger, E. A. (2004). Remembering emotional experiences: The contribution of valence and arousal. Reviews in the Neurosciences, 15, 241-252. https://doi.org/10.1515/REVNEUR0.2004.15.4.241

Kondo, A., Takahashi, K., \& Watanabe, K. (2012). Sequential effects in face-attractiveness judgment. Perception, 41, 43-49. https://doi.org/10.1068/p7116

Kosonogov, V., Martínez-Selva, J. M., Torrente, G., Carrillo-Verdejo, E., Arenas, A., \& Sánchez-Navarro, J. P. (2019). Head motion elicited by viewing affective pictures as measured by a new LED-Based Technique. Multisensory Research, 32, 575-588. https://doi.org/10.1163/22134808-20191363

Kovalenko, A. A., Pavlenko, V. B., \& Chernyi, S. V. (2010). Reflection of the emotional significance of visual stimuli in the characteristics of evoked EEG potentials. Neurophysiology, 42, 70-79. https://doi.org/10.1007/s11062-010-9133-9

Lang, P. J., Bradley, M. M., \& Cuthbert, B. N. (1997). Motivated attention: Affect, activation, and action. In P. J. Lang, R. F. Simons, \& M. F. Balaban (Eds.), Attention and orienting: Sensory and motivational processes (pp. 97-135). Lawrence Erlbaum Associates.

Mathôt, S., Schreij, D., \& Theeuwes, J. (2012). OpenSesame: An open-source, graphical experiment builder for the social sciences. Behavior Research Methods, 44, 314-324. https://doi.org/10.3758/s13428011-0168-7 
Ritz, T., Thöns, M., Fahrenkrug, S., \& Dahme, B. (2005). Airways, respiration, and respiratory sinus arrhythmia during picture viewing. Psychophysiology, 42, 568-578. https://doi.org/10.1111/j.14698986.2005.00312.x

Sánchez-Navarro, J. P., Martínez-Selva, J. M., Torrente, G., \& Román, F. (2008). Psychophysiological, behavioral, and cognitive indices of the emotional response: A factor-analytic study. The Spanish Journal of Psychology, 11, 16-25. https://doi.org/10.1017/S1138741600004078

Schlenker, R., Cohen, R., \& Hopmann, G. (1995). Affective modulation of the startle reflex in schizophrenic patients. European Archives of Psychiatry and Clinical Neuroscience, 245, 309-318. https://doi.org/10.1007/BF02191873

Sokolov, E. N. (1960). Neuronal models and the orienting reflex .In M. A. Brazier (Ed.), The Central Nervous System and Behavior, (pp. 187-276). Macey.

Stewart, N., Brown, G. D., \& Chater, N. (2005). Absolute identification by relative judgment. Psychological Review, 112, 881-911. https://doi.org/10.1037/0033-295X.112.4.881

Vrana, S. R., Spence, E. L., \& Lang, P. J. (1988). The startle probe response: A new measure of emotion? Journal of Abnormal Psychology, 97, 487-491. https://doi.org/10.1037/0021-843X.97.4.487

Wangelin, B. C., Löw, A., McTeague, L. M., Bradley, M. M., \& Lang, P. J. (2011). Aversive picture processing: effects of a concurrent task on sustained defensive system engagement. Psychophysiology, 48, 112116. https://doi.org/10.1111/j.1469-8986.2010.01041.x

$\begin{array}{ll}\text { Historial do artigo } \\ \text { Recebido } & 10 / 2019 \\ \text { Aceite } & 07 / 2020 \\ \text { Publicado } & 12 / 2020\end{array}$


Effects of order on valence and arousal 